\title{
Prevalence of pneumonia among under- five children in Este town and the surrounding rural kebeles, Northwest Ethiopia; A community based cross sectional study
}

\author{
Gedefaw Abeje Fekadu ${ }^{1,}$, Mamo Wubshet Terefe ${ }^{2}$, Getahun Asres Alemie ${ }^{2}$ \\ ${ }^{1}$ College of Medicine and health Sciences, Bahir Dar University, Bahir Dar, Ethiopia \\ ${ }^{2}$ College of Medicine and health Sciences, University of Gondar, Gondar, Ethiopia \\ Email address: \\ abejegedefaw@gmail.com (G. A. Fekadu), mamo_wubshet@yahoo.com (M. Wubshet), asresgetahun@ yahoo.com (G. A. Alemie)
}

\section{To cite this article:}

Gedefaw Abeje Fekadu, Mamo Wubshet Terefe, Getahun Asres Alemie. Prevalence of Pneumonia among under- five Children in Este Town and the Surrounding Rural Kebeles, Northwest Ethiopia; A Community Based Cross Sectional Study. Science Journal of Public Health. Vol. 2, No. 3, 2014, pp. 150-155. doi: 10.11648/j.sjph.20140203.12

\begin{abstract}
Introduction: Pneumonia causes about two million under five deaths each year, accounting for nearly one in five child deaths globally. Identifying its prevalence in under-five children and the associated factors is crucial to achieve MDG4 in developing countries. Objective: The main objective of this study was to assess the prevalence and factors associated with pneumonia among under-five children in Este town and surrounding rural kebeles, Northwest Ethiopia. Methods: Community based cross sectional study design was used. A total of 286 households with under-five children were selected by multistage sampling technique, 222 from rural and 64 from the urban kebeles ('Kebele' is the smallest administrative unit) proportional to the number of children in the respective kebeles. Two rural and one urban kebeles were selected by simple random sampling. Then households were selected by systematic random sampling technique. Trained nurses collected the data through face to face interview. Two health officers supervised the data collection process. Data were analyzed by stepwise binary logistic regression model. Result: The overall two weeks prevalence of pneumonia among under-five children was $16.1 \%$. Stunting, using charcoal for cooking, carrying the child on back during cooking, keeping cattle inside the main house and living in crowded house were the most important variables found associated with pneumonia among under-five children in this study. Conclusion and recommendation: The prevalence of pneumonia among under-five children in the study area was high. Nutrition interventions and introducing improved stoves to households may reduce pneumonia among children. Health education should be given for senior household members on the possible risk factors for pneumonia.
\end{abstract}

Keywords: Este, Under-Five, Pneumonia, Stunting

\section{Introduction}

The fourth Millennium Development Goal calls for reducing child mortality by two-thirds between 1990 and 2015 , but about 29,000 children under-five die worldwide every day, mainly from preventable causes [1, 2]. In 2007, 9.2 million children died before age five globally. Africa and Asia together accounted for 92 percent of these deaths [3]. Sub-Saharan Africa had an average under-five mortality rate of 172 deaths per 1,000 live births [1].

Ethiopia ranks $27^{\text {th }}$ in under-five mortality with 119 deaths per 1,000 live births [4]. Almost one in every ten babies born in Ethiopia does not survive to celebrate the first birthday [5].

Pneumonia, diarrhea, malaria, measles and AIDS accounted for about 50 percent of under-five deaths globally [1]. These and other neonatal diseases are major causes of death for $85 \%$ of African and $90 \%$ of Ethiopian children [6, 7].

Approximately two million children under five die from pneumonia each year, accounting for nearly one in five child deaths globally [8]. A study done by Luis Huicho et al identified that pneumonia caused about $20 \%$ of all under-five deaths in Peru [9]. Several studies done in different parts of Ethiopia showed that pneumonia is major cause of mortality and morbidity among under-five children $(3,10,11,12)$.

A study done in New Delhi slums estimated the overall prevalence of ARI among under-fives to be around 4.5 percent for a period of one month [13]. Azad found that 
$21.3 \%$ of children less than five years of age in Bangladesh suffered from ARI during the two weeks preceding the survey [14]. Previous studies done in Ethiopia showed varied and high levels of the prevalence of pneumonia among this age group $(5,15,16,17]$.

In developing countries, low socio-economic status, malnutrition, low birth weight, non-exclusive breastfeeding, indoor air pollution, crowding, parental smoking, zinc deficiency, mother's experience as a caregiver, mother's age, lack of education in the mother, humid conditions, high altitude, vitamin A deficiency, birth order and outdoor air pollution were found as possible risk factors associated with pneumonia among children $[11,14,17,18,19,20,21,22$, 23).

In Ethiopia, there are studies showing causes of mortality among children aged under-five years. However, little is known about the prevalence and determinants of each cause of mortality. Therefore this study was aimed to assess the prevalence of pneumonia among under-five children and factors associated with pneumonia among this age group in Este town and the surrounding rural kebeles, Northwest Ethiopia.

\section{Methodology}

A community based cross sectional survey was conducted from October 1 to October 15, 2009 in Este town and surrounding rural kebeles, Northwest Ethiopia. The study area consists of three urban kebeles ('kebele' is the smallest administrative unit) and six rural kebeles. There were six health posts and one health center providing health care services for the total population in the study area. Sample size was determined using single population proportion formula. Considering proportion of under-five children with pneumonia to be $9.3 \%$ (5), level of confidence $95 \%$, $5 \%$ margin of error, multiplying by 2 for design effect and adding $10 \%$ non response rate, a total of 286 households with under-five children were included in this study. Under-five children who have cough because of recent history of aspiration of a liquid or of a foreign body and confirmed diagnosis of tuberculosis were excluded from the study. A child with cough, fast breathing and/or danger signs was classified as a child with pneumonia based on the IMNCI classification.

Data were collected by six trained diploma nurses using structured Amharic (the local language) questionnaire through face to face interview. Two days training was given to data collectors on the objectives of the study, techniques of face to face interview, how to approach respondents, how to keep confidentiality, how to check if the child had chest in drawing, strider or general danger signs, and how to measure height and weight of the child. Pre-test was done in a similar setting outside the study area. Data collectors were supervised daily by two health officers. The supervisors received and checked the collected data for consistency and completeness. A suspended scale of $25 \mathrm{Kg}$ capacity graduated at $0.100 \mathrm{Kg}$ was used for weighing infants and children. After taking the weight of every child, the scale was checked for its accuracy. The scale reading was taken to the nearest $0.1 \mathrm{Kg}$. Length measurement on lying position was taken for children less than two years of age and height was taken for children 2-5 years of age. The reading was taken to the nearest $0.5 \mathrm{~cm}$. The collected data was coded and entered into SPSS version 16.0 window for analysis. EPI-info was used to calculate indices to assess nutritional status of the child. Bivariate and multiple logistic regression analysis were done; $\mathrm{p}$ value less than 0.05 was considered statistically significant.

\subsection{Ethical Consideration}

Ethical clearance was obtained from University of Gondar. Permission to conduct the research was also obtained from Este Woreda Health Department and kebele administrators before data collection. Informed consent was obtained from mothers after explanation of the purpose of the study, and the part they will take in the research. Any involvement was after their complete consent. Mothers of children were told that they had the right to withdraw from the study at any time during the interview. Children identified with untreated pneumonia during data collection were referred to health centres for treatment.

\section{Results}

\subsection{Socio-Demographic Characteristics}

A total of 286 mothers with under-five children were interviewed, out of which $64(22.4 \%)$ were urban residents and $222(77.6 \%)$ were rural residents. All mothers participated in the study and all the questionnaires were filled correctly.

The mean age of mothers was 28.4 and that of fathers was 36.8. About one-third of mothers and one fourth of fathers were between the age group of 25-30. Majority of the respondents (282) were Orthodox Christian and the rest (4) were Muslim. All the study participants belong to the Amhara ethnic group. Concerning educational status, 205 $(71.7 \%)$ of mothers and $119(42.5 \%)$ of fathers were illiterate. Among the interviewed mothers, the majority (239) were housewives. In terms of paternal occupation, 30(10.5\%) were government or nongovernment employees, 205 (71.7\%) were farmers, $21(7.3 \%)$ were merchants, $11(3.8 \%)$ were daily laborers and $14(4.5 \%$ ) were others (table 1).

Table 1. Selected socio demographic characteristics of parents. Este town and surrounding rural kebeles, South Gondar Zone, October 2009 ( $n=286$ mothers and 280 fathers)

\begin{tabular}{llll}
\hline Variable & Category & $\begin{array}{l}\text { Number } \\
\text { (n) }\end{array}$ & Percent (\%) \\
\hline Residence & Urban & 64 & 22.4 \\
& Rural & 222 & 77.6 \\
Educational & Illiterate & 205 & 71.7 \\
status & read write & 34 & 11.9 \\
of mothers & grade 1 to 6 & 17 & 5.9 \\
& grade 7 to 12 & 16 & 5.6 \\
\hline
\end{tabular}




\begin{tabular}{llll}
\hline Variable & Category & $\begin{array}{l}\text { Number } \\
(\mathbf{n})\end{array}$ & Percent (\%) \\
\hline & Above grade 12 & 14 & 4.9 \\
Educational & Illiterate & 119 & 42.5 \\
status & read write & 93 & 33.2 \\
of fathers & grade 1 to 6 & 23 & 8.2 \\
& grade 7 to 12 & 21 & 7.5 \\
& above grade 12** & 24 & 8.6 \\
& Housewife & 239 & 83.6 \\
Mothers & Employee & 14 & 4.9 \\
occupation & Farmer & 4 & 1.4 \\
& Merchant & 15 & 5.2 \\
& Daily laborer & 9 & 3.1 \\
& Other & 5 & 1.7 \\
Fathers & Employee & 30 & 10.5 \\
occupation & Farmer & 205 & 71.7 \\
& Merchant & 21 & 7.3 \\
& Daily laborer & 11 & 3.8 \\
& Other & 14 & 4.5 \\
\hline
\end{tabular}

NB: percentages are to the nearest tenth digit, So the total may not add up exactly to 100 .

Of all the under-five children included in the survey, 148 $(51.7 \%)$ were male and $138(48.3 \%)$ were females. Most children $(84.3 \%)$ were delivered at home. The mean age, weight and height (length) of the under-five children were $26.1 \pm 14.0$ months, $10.11 \pm 2.49 \mathrm{~kg}$ and $77.16 \pm 11.74 \mathrm{~cm}$ respectively. More than one fourth of children (26.9\%) were between the age groups of 24-35 months.

Only 13 mothers remembered the weight of their child at birth. Regarding the nutritional status of under-five children, $61.5 \%, 39.2 \%$ and $8.7 \%$ were stunted; underweight and wasted respectively (table 2 ).

Table 2. Selected characteristics of under-five children, Este town and surrounding rural kebeles, October $2009(n=286)$

\begin{tabular}{|c|c|c|c|}
\hline Variable & Category & $\begin{array}{l}\text { Number } \\
\text { (n) }\end{array}$ & $\begin{array}{l}\text { Percent } \\
(\%)\end{array}$ \\
\hline \multirow{3}{*}{$\begin{array}{l}\text { Place of } \\
\text { delivery }\end{array}$} & Home & 241 & 84.3 \\
\hline & Health center & 40 & 14.0 \\
\hline & Hospital & 5 & 1.7 \\
\hline \multirow{3}{*}{ BF history } & Exclusive BF & 240 & 83.9 \\
\hline & Mixed BF & 39 & 13.6 \\
\hline & Feed other than BM & 7 & 2.4 \\
\hline \multirow{3}{*}{$\begin{array}{l}\text { Immunization } \\
\text { history }\end{array}$} & Fully immunized & 220 & 76.9 \\
\hline & Partially immunized & 38 & 13.3 \\
\hline & No immunized at all & 28 & 9.8 \\
\hline \multirow{6}{*}{ Birth order } & First & 57 & 19.9 \\
\hline & Second & 62 & 21.7 \\
\hline & Third & 52 & 18.2 \\
\hline & Fourth & 38 & 13.3 \\
\hline & Fifth & 28 & 9.8 \\
\hline & Sixth and above & 49 & 17.1 \\
\hline \multirow{2}{*}{ Weight for age } & Normal & 174 & 60.8 \\
\hline & Underweight & 112 & 39.2 \\
\hline \multirow{2}{*}{ Height for age } & Normal & 110 & 38.5 \\
\hline & Stunted & 176 & 61.5 \\
\hline \multirow{2}{*}{$\begin{array}{l}\text { Weight } \\
\text { height }\end{array}$} & Normal & 261 & 91.3 \\
\hline & Wasted & 25 & 8.7 \\
\hline \multicolumn{4}{|c|}{ Age (in month mean $=26.1 \mathrm{SD}=14.0$ range $=1-59$} \\
\hline
\end{tabular}

$\mathrm{NB}$ : percentages are to the nearest tenth digit, so the total may not add up exactly to 100

\subsection{Housing, Environmental and Related Characteristics}

The majority of the houses (98.3\%) had earthen floor and their wall was made of wood with mud $(99.3 \%)$. About two-thirds of the houses had roof with corrugated iron sheets One hundred fourteen $(39.9 \%)$ houses were severely crowded. Only $169(59.1 \%)$ houses had windows. In 177 $(61.9 \%)$ of the households, cattle used to live in the main house with people. Two hundred eighty four (99.3\%) households used open fire or stove without chimney inside the main house for cooking. The main types of fuel used for cooking were wood (in $99 \%$ of the households), charcoal (in $24.8 \%$ of the households) and cow dung (in $76.9 \%$ of the households). No more than $6(2.1 \%)$ houses were ventilated when the level of ventilation was measured by the ratio of total window to floor area. About 144 (50.3\%) children were carried on back during cooking which exposes them to high indoor pollution.

\subsection{Signs and Symptoms of Pneumonia}

From those children included in the survey, 81(28.3\%) were sick at the time of data collection or within the last two weeks. Among these, 59 (20.6\%) had cough at the time of survey or within the last two weeks before the survey. Forty-five children $(15.7 \%)$ had fast breathing. Twenty-two $(7.7 \%)$ children had fever. Wheezing, chest in drawing and strider were reported in $24(8.4 \%), 6(2.1 \%)$ and $5(1.7 \%)$ of children respectively.

\subsection{Prevalence of Pneumonia among under - five Children}

Among 286 children included in the study, 59 (20.6\%) had cough at the time of interview or within the last two weeks. This figure represents the two week prevalence of ARI among under-five children in the study area. Among these children, $41(14.33 \%)$ had only history of fast breathing, 3 had both general danger sign and fast breathing and only one child had convulsion with no fast breathing which is one of the general danger signs. Therefore, the prevalence of pneumonia among under-five children at the time of survey or within the last two weeks was $16.1 \%$.

\subsection{Factors Associated with Presence of Pneumonia}

Different parental, childhood, environmental and household variables were tested for their association with the presence of pneumonia among under-five children by binary logistic regression analysis. First the association of each variable with the occurrence of pneumonia among under-five children was assessed by the classical binary logistic regression, and then variables which were significant at 0.05 significant levels were entered into the final model to control confounding.

\subsection{Socio-Demographic Characteristics}

Among the factors related with parents, age of mother, residence, mother's occupation, and economic status of 
parents demonstrated significant association with the presence of pneumonia among under-five children at unadjusted state. But father's occupation, smoking and educational status of parents did not illustrate significant association in this study. When all the variables with p-value less than 0.05 were analyzed by logistic regression all parental factors did not show significant association.

An odds ratio for religion and ethnicity of parent's was not computed as all children with pneumonia belong to parents who are Orthodox Christian and all the parents are Amhara by ethnicity.

From the child related variables, only height for age of the child was significantly associated with the presence of pneumonia among under-five children. This variable furthermore demonstrated significant association when adjusted for other variables. The age of the child showed negative relationship with the occurrence of pneumonia in children; however the association was not statistically significant.

\subsection{Housing, Environmental and Related Characteristics}

This study revealed that the prevalence of pneumonia among under-five children was not associated with use of cow dung for cooking and main material of floor of the house.

Charcoal use for cooking, carrying the child on back during cooking, cooking within the main house, keeping cattle in the main house, type of roof of the main house and household crowding status were found as important determinant factors for the development of pneumonia among under-five children. A child who lived in thatch roofed house was two and half times more likely to develop pneumonia than a child who lives in a house with corrugated iron sheet [Adj. OR 2.51, 95\% CI: 1.02-5.73].

Children who live in severely crowded house were more likely to have pneumonia with statistically significant difference than children who lived in under crowded house [Adj. OR=4.057, 95\% CI: 1.173-14.031].

Carrying the child on back during cooking and using charcoal for cooking were other variables that showed positive significant association with pneumonia among under-five children. A child carried on back during cooking was five times more likely to develop pneumonia than a child who was not carried [Adj. OR=5.38, 95\% CI: 2.13-9.65]. Similarly, a child whose parents used charcoal as main fuel was more likely to have pneumonia than those who did not use [Adj. OR=7.41, 95\% CI: 2.75-19.95]. Children who lived in a house where cattle were kept inside were also more likely to have pneumonia than a child who lived in a house where cattle were not kept inside [Adj. $\mathrm{OR}=3.264,95 \%$ CI: 1.10-9.65].

An odds ratio for use of wood for cooking, type of stove, level of ventilation and main material of the wall could not be computed as the majority of the households had similar characteristics.

\section{Discussion}

The overall two week prevalence of acute respiratory infection and pneumonia among under-fives was $20.6 \%$ and $16.1 \%$ respectively. ARI prevalence of the study area was higher compared to the regional $(9.3 \%)$ and national $(12.9 \%)$ figures of 2005 [5]. The case definition used and skill of the data collectors might be the reasons for the discrepancy. This figure was also higher than rates reported by other studies. A community based study in Tigray showed that the incidence of ARI was 5.53 per child-year [22]. This may be due to recall bias and seasonal variation. The other possible explanation for this variation was the fact that prevalence rate measures the amount of pneumonia cases that was present already in population while incident rate measure the rapidity with which new pneumonia cases develop over time. Another study in New Delhi estimated the overall prevalence of ARI among under-fives to be 4.5 for a period of one month [21]. However, the overall prevalence of ARI among under-fives in this study was comparable to a cross-sectional study conducted in Shebedino wereda $(21 \%)$ and in Bangladesh $(21.3 \%)$ [14, 24] The prevalence of pneumonia $(16.1 \%)$ in this study was significantly higher than the prevalence investigated by Dessaleg (8.9\%). This variation might be also due to the case definition used and the skill of the data collectors.

In this study, variables related with parents did not show statistically significant association with presence of pneumonia among under-fives. This finding was in contrast with studies in Bangladesh and Shebedino wereda [14, 24].

Stunting was significantly associated with the presence of pneumonia among under-five children. Stunted children were two and half times more likely to develop pneumonia than those who were not stunted. This result was consistent with a study in Bangladesh [14]. The possible reason why stunted children had more odds of developing pneumonia was that stunting shows long term malnutrition, which weakens the child's immunity and makes the child vulnerable to pneumonia.

From variables related with housing and environmental conditions, the main material of the roof was found statistically significant with the presence of pneumonia. The risk of developing pneumonia among under-five children who lived in thatch roofed house was 2.5 times higher compared to children who lived in corrugated iron roofed house. The possible reasons were that thatch roofed houses in the study area were less likely to have windows compared to corrugated roofed houses. The other possible explanations were people in the study area might not cook inside corrugated iron roofed houses and cattle are usually kept inside thatch roofed house.

Charcoal use was acknowledged as an important risk factor for pneumonia among under-fives in this study. Children from households who used charcoal were seven times more likely to develop pneumonia than those who did not use. Children who were carried on their mother's back during cooking were also more likely to develop pneumonia 
than those who were not. This is due to high indoor air pollution from biomass fuels. Air pollutants associated with biomass fuel use may adversely affect specific and non-specific host defences of the respiratory tract against pathogens. This finding is consistent with other studies [19, 24, 25, 26].

Children from severely crowded houses were four times more likely to develop pneumonia compared to children from under-crowded houses. Crowding at home increases risk of transmission of illness. This was consistent with other findings [28].

According to this study, keeping cattle in home with people is an important risk factor for pneumonia among under-fives. This may be due to the fact that when cattle are kept at home, the house is more likely to have poor sanitation, to be damp and humid.

\section{Conclusion and Recommendation}

Reducing under-five mortality and morbidity involves studying the major causes of mortality and morbidity, and identifying the most important factors associated with these causes, thus applying the findings to child health policy with the goal of reducing child morbidity and mortality. The results of this study found high prevalence of pneumonia among under-fives in the study area. Under nutrition, charcoal use, carrying the child on back, living in crowded house, living in thatch roofed house and keeping cattle inside the main house with the child were important factors found associated with the presence of pneumonia among under-fives.

Based on the above findings and conclusions, the investigators recommended the following points.

- The wereda health office in collaboration with the wereda energy and minerals office need to introduce stoves that use fuel more efficiently and produce less smoke than the traditional stove.

- The wereda health office in collaboration with the wereda rural and agricultural office need to improve the nutritional status of children in this area.

- The wereda health office should provide health education for care givers about health benefits of ventilated and improved housing conditions, to use separate kitchen, not to carry the child on back during cooking and to use separate house for cattle.

- Further study to see the level of association with some variables in which the association could not be established because of homogeneous population by including larger area.

\section{Acknowledgements}

We would like to thank University of Gondar for financial support of this study. We are also grateful for the cooperation of data collectors and the study participants.

\section{References}

[1] WHO, Department of Economic and Social Affairs, Statistics Division. Progress towards the Millennium Development Goals, 1990-2005. [Date accessed July 10, 2009]. Available from:

URL:

http://unstats.un.org/unsd/mi/goals_2005/goal_3.pdf

[2] Tadesse H, Amare A, Woldie M. Predictors of defaulting from completion of child immunization in south Ethiopia. BMC Public Health. [online] May, 2009 [accessed on June 15, 2009] 9:150. Available from: URL: http://www.pubmedcentral.nih.gov/articlerender.fcgi?tool=p ubmed\&pubmedid19463164

[3] Girma B. Epidemiological assessment of determinants and causes of under-five child mortality in Jimma town: Is HIV/AIDS influencing the pattern of child mortality. Thesis. AAU electronic library [unpublished].

[4] UNICEF. The state of the world's children 2009. Maternal and newborn health. [Date accessed May 26 2009] Available from:

URL:

http://www.unicef.org/publications/files/SOWC2009MainR eport03112009.pdf

[5] Central statistics authority. Ethiopian demographic and health survey, 2005. Addis Ababa, Ethiopia

[6] WHO, Global Burdon of disease. Causes of death in neonates and children under five in the African region. First published on 2004, updated 2008. [Date accessed May 30, 2009] available from :URL: http://www.who.int/child_adolescent_health/media/causes_d eath_u5_neonates_afropdf

[7] Federal Ministry of Health, Family health department. National strategy for child survival in Ethiopia. July 2005. Addis Ababa, Ethiopia.

[8] Child info, Statistics By area. Monitoring the situation of children and women. Pneumonia is the leading killer of children. [Date accessed June 17, 2009] Available at http://www.childinfo.org/pneumonia.html

[9] Huicho L'Trelles M' and Fernando Gonzales F. National and sub-national under-five mortality profiles in Peru: a basis for informed policy decisions. BMC Public Health [Serial online] July 4, 2006 [Date accessed June 16 2009]; 6(173). Available from: URL: http://www.pubmedcentral.nih.gov/tocrender.fcgi?iid=12647 6

[10] Deribew A, Tessema F, Girma B. Determinants of under-five mortality in Gilgel Gibe Field Research Center, Southwest Ethiopia. Ethiopian Journal of Health Development. 2007;21(2):117-124

[11] Emmelin A and Wall S. Indoor Air Pollution: A poverty-related cause of mortality among children of the world. CHEST [Serial online] November, 2007 [Date accessed on 11-6-2009]; 132(5):1615-1623 Available from: URL:

http://www.chestjournal.org/content/132/5/1615.full?sid=7e a37112-999 d82844b83548

[12] Teka T. Causes of child mortality in Gondar hospital. Ethiopian Journal of health. Development. 1996, 10(3): 145 $-1481$ 
[13] Gupta R, Kumar A, Singh P. Factor analysis of acute respiratory infections among Under Fives in Delhi Slums. Brief report. Indian Pediatrics [Serial online] 1999 [Date accessed June16 2009]; 36(1):1144-1149. Available from: URL: http://indianpediatrics.net/99nov01.htm

[14] Azad k. Risk factors for acute respiratory infections (ARI) among children under five years in Bangladesh. Journal of Scientific Research. [Serial online] 2009 November 20 [Date accessed June 12, 2006]; 1(1), 72-81. Available from: URL: http://www.banglajol.info/index.php/JSR

[15] Ali M, Asefaw T, Beyene H, Byass P and Hisabu MS, Pederson F. A community-based study of childhood morbidity in Tigray. Ethiopian Journal of Health Development. 2001, 15(3):165-172.

[16] Tessema T, Hailu S, Anbebir S and Mitikie G. Household illness prevalence and its determinants in the under five children, North Western Ethiopia. Ethiopian Journal of Health Development. 2000, 15 (3):173-178

[17] Dessalegn B. Household fuel use and acute respiratory infection among younger children: An Exposure Assessment in Shebedino Woreda, Southern Ethiopia. Thesis. AAU electronic library [unpublished].

[18] Rudan I, Boschi-Pinto C, Biloglav Z, Piloglav Z, Mullholand $\mathrm{K}$, Campbell. Epidemiology and Etiology of Childhood Pneumonia. Bulletin of the World Health Organization [Serial online] May 2008 [Date accessed June 6, 2009]; 86 (5): 408-416. Available from: URL: http://www.who.int/bulletin/volumes86/5/07-048769/en/ind ex.html
[19] BIO-MEDICINE. Study of energy and health in Africa focuses spotlight on charcoal and forest management. 31-March-2005 [Date accessed on 10-6-2009]. Available from: URL: http://news.bio-medicine.org/medicine-news-2/

[20] Mitra N. A longitudinal study on ARI among rural under fives. Indian journal of community medicine [Serial online] 2001January - March [Date accessed June 25, 2009]; 26(1). Available from: URL: http://www.indmedica.com/journals.php?journalid=7\&issuei $\mathrm{d}=47 \&$ articleid $=573$ article

[21] Kebede D. Risk factors for acute lower respiratory infections in under-five children in Addis Ababa. Article Review. Ethiopian journal of health development.1997, volume 11 special issue.

[22] Persson L. The unfinished child survival revolution: the role of nutrition. Scandinavian Journal of Nutrition. [Serial online] 2005 [Date accessed June 23, 2009]; 49 (4): 146 - 150. Available from: URL: http://www.foodandnutritionresearch.net/index.php/fnr/articl e/viewFile/1541/

[23] Cardoso M, Cousens S, Siqueira L, Alves F and Angelo L. Crowding: risk factor or protective factor for lower respiratory disease in young children? BMC Public Health [Serial online] June 3, 2004 [Date accessed May 25, 2009]; 4(19). Available from: URL: http://www.pubmedcentral.nih.gov/tocrender.fcgi?iid=9515 